\title{
Högskolans viktigaste bidrag till den regionala utvecklingen sker genom akademiska yrkesutbildningar i partnerskap
}

Jag argumenterar för en integrering av det individuella lärandet, utbildningen, med det kollektiva lärandet, forskningen, i ett lokalt lärande, där företag och organisationer också lär sig tillsammans med studenter och forskare. Högskolans historia som yrkesutbildare måste balanseras av högskolans kritiska självständighet och förmåga att tala sanning till makten.

\section{Individuellt, kollektivt och lokalt lärande}

I slutet på 1990-talet skrev John Bowden och Ference Marton The University of Learning, en bok som har bidragit till en viss omfokusering av den högre utbildningens uppmärksamhet från vad läraren undervisade om till vad studenten och forskaren - lärde sig. Detta var strax innan den stora Bolognaprocessen svepte igenom den svenska högskolans utbildningar med sina detaljerade lärandemål och därtill kopplade examinationer. Boken har undertiteln Beyond Quality and Competence, och avslöjar därmed vilken skepsis de redan då hade mot dessa båda luddiga och uttjatade begreppen. Bland flera lärdomar jag bär med mig från den boken är synen på lärandet som kan uppträda på tre sätt, som motsvarar vad som åtminstone då kallades högskolornas tre uppgifter: utbildning,

How to cite this book chapter:

Casson, A 2015 Högskolans ansvar: Principer för utveckling av den högre utbildningen. London: Ubiquity Press. DOI: http://dx.doi.org/10.5334/bap.h License: CC-BY 3.0 
forskning och, "den tredje uppgiften", eller med andra ord, samverkan med det omgivande samhället.

Utbildning motsvarar, i Bowden och Martons resonemang, det individuella lärandet, processen där en individ förstår och tillgodogör sig något som troligen redan är känt av andra - läraren, till exempel. Forskningen motsvarar det kollektiva lärandet; mänskligheten som kollektiv lär sig något nytt. Fokus på lärandet och kontrasten mellan de två belyser på ett bra sätt vad som förenar dem och vad som skiljer dem åt. Men det som verkligen öppnade ett nytt fönster i mitt tänkande och kastade nytt ljus över välkända fenomen, var när de kallade samverkansuppgiften för det lokala lärandet. ${ }^{133}$ Lärandet kan då både vara individuellt i form av yrkesutbildning, fortbildning, uppdragsutbildning och så vidare, eller kollektivt, i form av gemensamma forsknings- och utvecklingsprojekt - men är kopplat till en gemensam plats, locus, där forskare, lärare, studenter, yrkesverksamma i företag och organisationer i en stad eller en region samverkar kring gemensamma uppgifter, för att lära sig. Om en sådan syn på högskolans uppgifter kunde prägla inte bara vår syn inom högskolan på vår uppgift utan också omvärldens, tror jag att det kunde få stora konsekvenser. Det är inte högskolan som har till uppgift att lära ut eller berätta vad man kommit fram till i sin forskning och därmed "tillämpa" forskningen eller "popularisera" utan det är vad - och hur - man tillsammans kan lära sig något nytt.

Innan jag går in på vad jag tror är en förenklad syn på hur forskningen bidrar till regionens välfärd, dock, behöver jag resonera om den lika förenklade synen på högskolan som leverantör av yrkeskompetens. De flesta regioner i Sverige utanför storstäderna har problem med att förse arbetslivet med välutbildade ungdomar som kan ersätta det stora antalet som lämnar sina yrken med ålderspension. Vad har högskolan för roller att spela här? Hur kan det individuella lärandet bidra till och uppgå i ett lokalt lärande? Kan man förena regionens krav med akademins krav?

\section{Högskolans historia är yrkesutbildningens}

Högskolan som den ser ut idag har vuxit fram ur behovet av yrkesutbildning. Hela denna mångfald av institutioner för högre utbildning i alla länder världen runt - universiteten i Bologna och Oxford, järnvägsuniversitetet i Jiaotong, Gandhi Open University med sina 3,5 miljoner studenter, polishögskolor och militärhögskolor, Liberal Arts Colleges och prästseminarier, Harvard och Yale och Ohio State, Lund och Luleå - alla har de ursprungligen sysslat med förberedelse för ett yrkesliv. Och gör så fortfarande, de flesta även i en relativt snäv bemärkelse, där kunnandet i ett bestämt yrke tydligt överskuggar alla ambitioner att bibringa bildning eller så kallade generiska förmågor.

När jurister från hela Europa för tusen år sedan drog sig mot Bologna för att lära sig den romerska rätten skapades en av de viktigaste grunderna för

133 Bowden and Marton 1998, s 5-6. 
uppbyggnaden av Europas rättsstater. Yrkesutbilding för jurister, alltså. Ditresande studenter slog sig samman i nationer och avlönade sina lärare. Andra skrån följde efter. Den högre utbildningens förhistoria i Europa, under de tusen åren som föregick Bologna 1088, hade förstås varit kyrkans. Det var i klostren och katedralskolorna som den bokliga lärdomen, studiet av de heliga skrifterna, pågick. När sedan den grekiska tankevärlden genom nyupptäckten och översättningen av Aristoteles efter 1200-talet spred sig genom Europa, var det universiteten som fick ta sig an uppgiften att förlika kyrkans läror med antikens filosofi och naturvetenskap. Teologin fick därmed en betydande och självklar plats i de tidiga universiteten - yrkesutbildning för prästerskapet. Yrkesutbildningen för medicinare byggde i hög grad på Galenos, den grekiska läkaren från 100-talet vars skrifter styrde över västvärldens syn på människokroppen och dess sjukdomar $i 1500$ år.

När universiteten började växa fram i Norden under 1400- och 1500-talen var det också här framförallt som yrkesutbildning för prästerskapet; kyrkan fortsatte utöva sitt grepp över universiteten under sekler framöver. Uppsala universitet lades mer eller mindre ner bara ett femtiotal år efter instiftandet 1477 eftersom Gustav Eriksson i sin nya reformerade kyrka inte ville veta av någon prästerlig utbildning enligt den romerska läran. Det skulle dröja ytterligare femtio år innan den lutherska statskyrkan insåg att den också behövde välutbildade präster och universitetet därmed kunde få fart på verksamheten igen. En yrkesutbildning till präst innehöll - och innehåller - dock inte mycket av det man enligt dagens snäva definition av yrkesutbildning borde kunna för att arbeta som präst: ekonomi, personaladminstration, psykologi, pedagogik, kan man tänka sig. Snarare fick man ägna sig åt studiet av den heliga skriften och dess uttolkningar, tillsammans med en dos aristotelisk filosofi, vilket förstås ger rikligt med tillfällen att också söka sin egen sanning. För, som dansken Bo, universitetslärare i Paris på 1200-talet, skrev i sin Om det högsta goda: "Ty insikten i sanningen är en njutning. Det förstådda behagar den som förstår, och ju mer förunderligt och ädelt det förstådda är och ju skarpare förståndet är när det gäller att fullkomligt begripa det, desto större är den intellektuella njutningen."134 Och även om den högre utbildningen har sin upprinnelse i yrkesutbildningen, har den sin själ i sanningsökandet, kunskapen för dess egen skull.

\section{Mera teori, mera praktik}

Kunskapen för dess egen skull har alltid betraktats som motpolen till den slags yrkesutbildning som ser till att du kan det du behöver det första året på det nya jobbet. Och det är en vanlig föreställning, tror jag, att högskolans utbildningar

${ }^{134}$ Citerat ur Anders Piltz, Medeltidens tankevärld 1978, s 212. Dansken Bo, också känd under sitt latinska namn Boethius de Dacia, var en för sin tid radikal filosof som vågade hävda i sin Det högsta goda eller Över filosofens liv (c 1170) att det var genom filosofens rationella betraktelse av det sanna och det goda som människan kunde uppnå visdom. 
än idag placerar sig på en punkt någonstans mellan dessa två ytterpolerna; på senare år, tycks det, i allmänhet stadd i en snabb utveckling i riktning mot ytterpolen yrkesutbildning. Akademi och yrke skulle polerna kunna kallas, eller teori och praktik. Men min tes här är att man i grunden inte bör röra sig på en sådan axel alls; axeln är felkonstruerad, precis som en axel mellan teori och praktik är felkonstruerad. Troligen beror en sådan besvärlig föreställning på människans eviga lust och vilja att skapa dikotomier och motsatspar överallt: antingen - eller: A eller B, X eller Y. I stället tror jag högskoleutbildning skulle vara betjänt av att vi ser $t v a ̊$ axlar, oupplösligt kopplade med varandra och beroende av varandra; den ena axeln leder från mindre (yrkesanknuten) "praktik" till mera; och den andra från mindre sanningsökande eller (akademisk) "teori" till mera.

I valet mellan teori och praktik väljer jag således mera av båda. Alltså INTE:

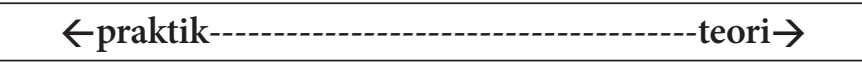

UTAN:

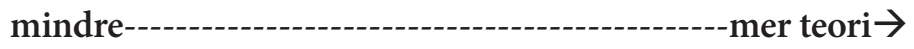

$$
\begin{aligned}
& ++++++++++++++++++++ \\
& \text { mindre- } \\
& \text {-mer praktik } \rightarrow
\end{aligned}
$$

Universiteten växte alltså fram ur samhällets yrkesbehov men knappast, i någon modern mening, i nära samverkan med yrkesutövarna. Universiteten levde ett eget liv, uppfostrade sina egna lärare och det blev framförallt unga människor - inte så sällan riktigt unga, både 13- och 15-åringar skrevs in i Uppsala - som tog del av undervisningen innan de påbörjade någon yrkesbana. Sedan återvände de aldrig, om det inte var av nostalgiska skäl eller för att firas som jubeldoktor.

Många av de tidigare europeiska universiteten blev helt självständiga med egna tillgångar med tillräcklig avkastning, egna lagar och rättsväsenden, egna byggnader och campus utanför stadens hank och stör - alla väsentliga förutsättningar, med andra ord, för att bli elfensbenstorn. Det var 1800-talets blomstrande industrialism och det nya samhället som växte upp omkring den som krävde bättre utbildat yrkesfolk inom i stort sett alla professionella yrkeskategorier såsom vi känner dem idag. De amerikanska land-grant universities fick egna tillgångar i form av mark på 1860-talet för att kunna vara självförsörjande, med den främsta avsikten att gagna produktionen; det var utbildningar i lantbruksvetenskap, naturvetenskap och teknik som skulle prioriteras. De universitet som byggdes upp i Manchester, Birmingham och Glasgow, byggdes i rött tegel, redbrick, mitt i de städer vars industrier och samhällsinstitutioner de hade att 
försörja. Och inte långt efter dem kom högskolorna i Stockholm och Göteborg, utan den gamla kopplingen till kyrkan men nära förbundna med folkbildningen och sina värdstäder. På båda hållen växte de nya högskolorna så sakteliga fram under 1800-talets senare hälft med öppna föreläsningsserier som reaktion mot de gamla universitetens tvångsämnen och examina. Snabbt växte extramurala kurser och program för en allmänhet som inte tillhörde universitetseliten men som ändå behövde förkovra sig. Bara ett sådant ord som extramurala - utanför murarna. Murarna runt lärdomen var alltså det givna; att unga män skulle ägna just tre år av sitt liv i gränsen mellan ungdom och yrkesliv åt studier bland jämnåriga i en främmande miljö bakom murarna var lika givet.

Naturvetenskapen hade vuxit fram inom universiteten men under 1800-talets senare del togs efterhand också ingenjörskonsten in i finrummen. Fortfarande var det dock den humanistiska fakulteten som stod högst i rang och där var inte yrkeskopplingen särskilt tät. Sjuksköterskeskolorna och lärarseminarierna som hade grundats under senare delen av 1800-talet inkorporerades i högskolan hundra år senare, liksom ingenjörsutbildningen som vuxit fram ur bergsskolor och slöjdskolor. Sveriges första institution för högre utbildning i teknik startade 1822 i Falu Bergsskola. Teknisk utbildning i anslutning till stormaktstidens skattkista, Falu koppargruva, hade förstås förekommit i mer eller mindre lärlingsliknande former sedan urminnes tider, men det nya var att den fick en särskild byggnad med särskilda lärare och en kursliknande struktur, skild, om än inte så långt, från den praktiska malmhanteringen. Kopparbergets betydelse minskade dock i takt med att Stockholms växte och Bergsskolan flyttade sin verksamhet dit 1869 för att bilda vad som 1877 blev Kungliga Tekniska Högskolan.

\section{Om akademisk yrkesutbildning som verksamhetsutveckling}

Jag argumenterar på annat ställe för att de svenska högskoleutbildningarna har blivit alltför snävt yrkesinriktade. EU, regeringen, regionen, arbetsgivare och fack, inte minst studenterna själva är fokuserade på en enda fråga - vad ska du bli? Och hur fort blir du det? Och hur mycket kommer du att tjäna? När ska det humankapital som du utgör kunna sättas i produktivt arbete som gagnar dig själv och din karriär, företagen och samhällstjänsten, BNP och tillväxten i företaget, regionen, Sverige, Europa? Blir de kompetenser du förvärvar under din utbildning de rätta för att passa in företagens och samhällets behov av kompetens? Kort sagt, blir du lönsam, lille vän?

Inget fel i dessa frågor. Alla behöver vi försörja oss, de flesta vill nå framgång i ett yrke, och för de allra flesta betyder det någon form av anställning. Fel blir det dock om frågan om den kortsiktiga anställningsbarheten förblir den enda frågan. Det måste till en anna fråga också: inte vad ska du bli, utan vem ska du bli? Hur ska du bilda dig, hur ska du odla dina handlingsförmågor? Hur ska du bäst förbereda dig för fyrtio yrkesår med uppgifter som varken du eller någon annan knappast ens kan sia om? Hur ska ditt omdöme utvecklas så att du kan bättre se och förstå dig själv och människorna omkring dig, samhällsinstitutionerna, de stora 
världsomspännande skeenden som påverkar din och alla andras vardag? Och hur ska du skaffa dig handlingsförmågan, makten, att i din tur påverka alla dessa?

I valet mellan akademi och yrke, mellan bildningen och utbildningen, mellan teori och praktik, mellan boken och verkstaden menar jag att vi alltid behöver både och. Och inte bara både och, utan mera av båda. Hur ska det gå till? Mera praktik måste väl tränga ut teorin, eller mera teori göra att praktiken inte får plats? Om vi istället erkänner att praktik och teori är oupplösligt förbundna med varandra; att de utgör varandras förutsättningar; att det inte finns en praktik utan en teori som kan beskriva den; att det inte finns en teori utan en praktik att referera till, så tror jag man undanröjer en del bekymmer som brukar uppstå när man ska utforma en utbildning.

Kanske kan det önskvärda förhållandet mellan de två aspekterna, teori och praktik, förtydligas i en fras som "akademisk yrkesutbildning". "Akademisk" kan visserligen uppfattas som ett skällsord i vissa kretsar, just i ordets koppling till onyttig teori och improduktiva spetsfundigheter. Men det är en association som borde kunna bekämpas med ett envist och stolt bruk av ordet i betydelsen självständigt, noggrant, kritiskt tänkande. Bilder och slagord, slogans, är viktiga. De styr vårt tänkande och det är viktigt att de blir rätt. De är förgrovningar, onyanserade och grovhuggna, och så måste de vara om de ska kunna hållas i minnet också av den som har hundra andra intressanta saker att tänka på. Jag vet inte om "akademisk yrkesutbildning" är just ett sådant slagord som kan hjälpa oss framåt. Jag hoppas det.

Vad skulle akademisk yrkesutbildning kunna vara? Ja, praktikgrundad utbildning, till att börja med. Kanske inte så helt annorlunda än alla de goda former som vuxit fram under årens lopp i flera av högskolans stora yrkesutbildningar: studenter som deltar successivt alltmera aktivt i hela bredden av arbetsplatsens uppgifter, i vården, skolan, den kreativa arbetsplatsen, industriproduktionen, administrationen, rättssalen. De socialiseras in i ett arbete, ett yrke och måste därför samtidigt odla förmågan och få tillfället att ta ett steg tillbaka och reflektera över vad som är bra eller mindre bra och varför. Med sin kritiska, nyfikna blick ser studenten på ett annat sätt än de som varit där i tio eller tjugo år. Hon kan uppmuntras att delta i ett samtal om utveckling och får stöd av handledare som också får tid, stöd och stimulans att utveckla sitt eget seende och bredda sina perspektiv. Genom att både delta i, beskriva och tillsammans med andra djupt begrunda tillverkningsprocessen i en fläktfabrik, genom att både delta i vården av människor och fördjupa sig i hur de möten mellan människor som vården grundas på sker, utvecklas både en skicklighet att hantera teoretiska beskrivningsmodeller - nya sätt att se - och en hantverksmässig skicklighet - bättre sätt att göra.

I detta dynamiska möte finns också fröet till utveckling för en verksamhet. Studenten är inte den som inte vet nånting - "vad lär de sig nuförtiden på högskolan?" - och som måste stöpas i samma mall som handledaren. Studenten och handledaren utvecklas tillsammans och ser genom sin dialog med varandra och med sin verksamhet ständigt nya perspektiv. Kliniska lektorer kalllas, till exempel, de verksamhetsförlagda högskolelärarna i vården och sådana 
skulle kunna finnas i snart sagt alla arbetsplatser som är intresserade av ett sådant kompetenstillskott och vågar öppna sig för kritik och den utveckling den kan föra med sig.

Akademisk yrkesutbildning som verksamhetsutveckling, skulle kunna vara en sammanfattning på detta. Lite för långt för en slogan, kanske, men den får duga så länge. Akademisk är den därför att den är kritiskt ifrågasättande, den är grundad på forskning och forskningens stringenta sätt att se på världen. Akademisk är den också därför att den ser längre än till yrkesutbildningen, den ser till hela studentens växande och bildning, hennes förmåga att ta sig an både yrket och livet. Tillsammans odlar de olika aspekterna en reflekterande handlingsförmåga, grundad i en mängd olika samarbetsformer. En utopi? Kanske, men det finns åtskilliga exempel som redan fungerar. Snarare ett ideal som kanske inte uppnås i alla sina beståndsdelar överallt men som ändå tjänar både som en utgångspunkt och som en fyrbåk för utveckling.

En sådan nära koppling mellan högskolan och arbetslivet skulle också kunna öppna för högskolan som regionens kunskapsport. Här sitter vi, åtminstone 300 forskarutbildade, i Dalarna. Vi läser forskningsrapporter, böcker och analyser dagarna i ända. Vi granskar dem, kritiserar och bearbetar dem i vår egen forskning och lägger fram våra rön i seminarier och i nya artiklar och böcker. Men hur mycket av allt detta någonsin når ut utanför våra väggar? I vissa verksamheter mer än i andra, är svaret. I vårdyrken, till exempel, verkar det finnas en mottaglighet för forskningsrön som få andra yrkeskategorier kan uppvisa. Av tradition, inte bara i Sverige, är kanske läkaryrket det som genom sina utbildnings- och karriärstrukturer skapar de bästa förutsättningar för att det kollektiva lärandet - forskningen - inte bara ska bli en del av det individuella lärandet - undervisningen - utan också av det lokala lärandet - samverkan. Universitetssjukhusen utgör ett typexempel på verksamheter som i sin struktur överbrygger gapet mellan akademi och praktik. Under de senaste decenniernas kamp för en självständig profession har sjuksköterskorna i både sin utbildning och praktik i kanske ännu högre grad konsekvent anammat forskningsresultat som grund i den evidensbaserade vården. Det har varit en viktig strategi, tycks det, för att komma ur både läkarens, omvärldens och deras egen nedärvda bild av sjuksköterskan som läkarens assistent. Av mina egna iakttagelser att döma, och inte minst i jämförelse med relationen mellan läkares och sjuksköterskors yrkesroller till exempel i UK, verkar strategin har haft viss framgång - även om en sådan framgång säkert påverkas av långt flera faktorer än bara hur man förhåller sig till forskningen.

Om det då fungerar inom vård- och medicinyrken att akademi och praktik tillsammans bildar arenor för lokalt lärande, hur ser det ut inom andra yrkesfält. Min överblick är naturligtvis bristfällig - vem överblickar alla samhällets yrkesfält? Genom decenniers erfarenhet av min egen högskolas och andras akademiska yrkesutbildningar kan jag nog hävda att det skulle kunna fungera betydligt bättre. Inom ungdomsskolan finns goda ansatser: gemensamt finansierade forskarutbildningstjänster där skollärare genomgår en forskarutbildning på 
halvtid medan de har halva sin undervisningsstjänst kvar; gemensamma forskningsprojekt; seminarieserier; examensarbeten - alla dessa och flera insatser därtill förekommer, även om det är i begränsad omfattning. Ännu ses de knappast som självklara inslag i de flesta skolors vardag. Och så är det inom många andra offentligfinansierade yrkesområden - socialtjänsten, den offentliga förvaltningen, polisen och rättväsendet för att nämna några: det finns goda exempel på gemensamma insatser som kan leda till forskningsbaserad verksamhetsutveckling men de kan knappast sägas vara systematiska eller prägla en lärande kultur.

I de grundutbildningar som leder till yrken som är mest frekventa inom den privata sektorn - ekonomutbildningar - finns inte heller en tradition av systematiskt och kontinuerligt lärande över gränserna mellan akademi och arbetsliv. Ekonomstudenters examensarbeten, som ofta undersöker empiri i företag och organisationer, utgör ett undantag. Andra stora och viktiga undantag finns också, självklart i samarbetet mellan t.ex. de tekniska högskolorna och storföretagens forsknings- och utvecklingsavdelningar. Men dessa är tämligen isolerade från verksamheten i stort. De fungerar oftast som innovationsverkstäder där man forskar fram nyheter som i gynnsamma fall kan ge upphov till nya eller förbättrade produkter och försäljningframgångar, i enlighet med samhällets helt förhärskande föreställningen om den linjära utvecklingsmodellen, som jag synar under nästkommande princip.

Bland ekonomer och administratörer i både offentlig- och privatfinansierade verksamheter syns inte många spår av gemensamma forskningsbaserade utvecklingskulturer. Där tycks estradören med de snyggt förpackade privatpsykologiska universalkurerna härska tämligen ohotat på utvecklingsdagar och kick-offs.

Men om akademin och arbetslivet tillsammans ska söka efter lösningar, vem är det då som ska ställa frågorna? Möjligen har ett av problemen som stått i vägen för ett närmande mellan akademin och arbetslivet varit att forskningen nästan alltid har ställt sina egna frågor och svaren har ekat i de egna seminarierummen och de - åtminstone förr - så svårtillgängliga tidskrifterna. Framgång har mätts av uppskattning bland de egna leden genom kollegornas uttalanden inför publicering i peer-review tidskrifter och vid tjänstetillsättningar eller genom statistiska mått såsom antal citeringar. Och då blir de mest intressanta frågorna de som har störst intresse för kollegorna. Forskningen blir inåtblickande och i takt med den tilltagande specialiseringen av disciplinerna och med den ökande dominansen av de korta artiklarna, som sällan innehåller mer än en dellösning i en dellösning, alltmer esoterisk.

\section{Och vem ska då tala sanning till makten?}

Ett lokalt lärande som uppstår i ett sådant samarbete mellan arbetsplatser och den högre utbildningen är naturligtvis inte utan en hel del problem. Om man för ögonblicket bortser från alla de praktiska problemen med placering och 
finansiering, med samarbets- och styrformer och så vidare, finns det ett övergripande principiellt bekymmer: Hur bevara och förstärka akademins autonomi i ett så nära umgänge med de starkt vinstmotiverade företagen och de alltmer tydligt mål- och resultatstyrda offentligfinansierade institutionerna? Hur ska studenter, lärare, forskare kunna vara ohöljt kritiska mot en verksamhet som de samarbetar så nära med, som kanske på ett eller annat sätt bidrar till att de får lön och mat för dagen? Finns inte en överhängande risk att studenter tidigt socialiseras in i attityder och arbetssätt som inte alls gagnar verksamhetens utveckling och inte heller studenternas utveckling mot fritt och kritiskt tänkande individer?

Makten, i form av de senaste decenniernas regeringar både i Sverige och resten av västvärlden, har varit konsekvent i att främja och hylla olika former av nära samarbete mellan framförallt näringslivet och den högre utbildningen. En stor brittisk rapport om befintliga och önskvärda samarbetsformer från 2012 inleds med ett citat som speglar den förhärskande synen: "Precis som medeltidens borgar gav styrka åt den tidens städer, och fabriker skapade välstånd under den industriella epoken, så utgör universiteten styrkans fundament i 2000-talets kunskapsekonomi." ${ }^{135}$ Rapporten beställdes av det brittiska utbildningsdepartmentet som där går under det talande namnet The Department for Business, Innovation and Skills. Stolta traditioner av humanistisk bildning finns förvisso kvar i de brittiska universiteten och försvaras i högtidstal men utgör en slags finkulturell glasyr på den egentliga kakan: universiteten är främst till för att gagna vinstdrivande affärsverksamhet och dess behov av lämplig arbetskraft och nya produkter.

Och vem ska då tala sanning till makten? Historikern Thorsten Nybom har varit en av dem som ihärdigt kritiserat den tilltagande sammanblandningen mellan vad han menar borde vara tre väl åtskilda institutioner: politiken, byråkratin och vetenskapen. Universiteten styrs, menar han, i alltför hög grad av forskningsmedel som fördelas av byråkrater i enlighet med politikens agenda. Rollerna blandas ihop och det uppstår ett intellektuellt skymningsland befolkat av hybridforskare som ägnar sig åt ideologiproduktion. ${ }^{136}$ Jag är övertygad om att det finns en motsvarande risk i att blanda utbildningsplatsen med arbetsplatsen; arbetsplatsens dominerande ideologi blir också utbildningens och påverkar därmed högskolans. Men det är väl just i detta som högskolans viktiga roll skulle kunna ligga, om man noggrant definierar och upprätthåller transparenta roller i samarbetet: att se, uppmärksamma, analysera och kanske i förlängningen förändra rådande praxis, normer och ideologier. På samma sätt

135 "Just as castles provided the source of strength for medieval towns, and factories provided prosperity in the industrial age, universities are the source of strength in the knowledge-based economy of the twenty-first century." Orden kommer från den inflytelserika Dearing report (2002) och står som motto för Lord Tim Wilsons rapport A Review of Business-University Collaboration. (Wilson 2012, s 2)

136 "The blurring of roles that we have seen is a consequence of the almost epidemic growth, since the 1970s, of the polycratical, intellectual hybrid sphere, which, especially in the medial arena, operates in the twilight zone between science, bureaucracy and politics..." (Nybom 2013, s 36) 
som man kan invända att vetenskapen aldrig helt kan undandra sig från ett ideologiskt sammanhang - det finns ingen värderingsfri forskning - kan man hävda att det inte finns någon värderingsfri utbildning. Den akademiska yrkesutbildnngen måste ha som syfte att lyfta fram och synliggöra dessa värden och att förmå studenter att självständigt ta ställning, att välja ståndpunkt utifrån självinsikt och klargjorda grundprinciper. Därmed förenas också högskolans bildningssträvan i den akademiska yreksutbildningen.

Universitetet brukar räknas som det västerländska samhällets mest bestående institution och, om man ser till dess tillväxt alltsedan 1100-talet, en av de mest framgångsrika. Som institution skulle man också kunna säga att det utgör Europas mest spridda och mest bestående bidrag till världens utveckling, även om spridningen till stor del skedde genom det flerhundraåriga rövartåget som kallas kolonialism. Universiteten har lyckats överleva och utvecklas tack vare balansen mellan oberoende $a v$ samhället och beroende på samhället. Genom att skissa en akademisk yrkesutbildning i nära partnerskap mellan akademi och arbetsliv har jag velat klargöra en del principer som kan lösa upp en synbar motsättning mellan praktik och teori, mellan högskola och vad som av dem utanför högskolan ofta kallas för verklighet. Jag har antytt hur både högskolan och arbetsplatsen kan tjäna på ett nära samarbete, ett samarbete som kan leda till en ständigt pågående utveckling i såväl arbetslivets som högskolans alla områden, vitaliserad av nyfikna och självständiga studenter.

Men det är inte bara studenterna på grundnivå som kan bidra till regionens utveckling, till lokalt lärande. Forskning och forskarutbildning har också en central roll att spela. I nästkommande princip visar jag att det kan gå till på ett annat sätt än man vanligen antar. 